\title{
Estudo do efeito da nitretação iônica a plasma na resistência ao desgaste do aço SAE 1020 utilizado em matriz de conformação
}

\author{
Study of the effect of the plasma ionic nitriding parameters in wear \\ resistance of SAE 1020 steel used in forming die
}

Miguel Rubira Danelon 1,", Fábio Soares², Marcos Dorigão Manfrinato ${ }^{1,2}$, Luciana Sgarbi Rossino $^{1,2}$

\begin{abstract}
RESUMO
O aço 1020, apesar de apresentar resistência mecânica adequada para conformação e corte do alumínio, sofre desgaste, diminuindo sua eficiência em serviço. Para evitar isto, pode-se recorrer a tratamentos termoquímicos, como a nitretação iônica a plasma, que promove a difusão do nitrogênio formando nitretos na superfície do material, aumentando a resistência ao desgaste, à corrosão e à fadiga do material. Assim, estudou-se o efeito do fluxo $(500 \mathrm{sccm}$ e $750 \mathrm{sccm})$, da temperatura $\left(400,450,500,550\right.$ e $\left.600^{\circ} \mathrm{C}\right)$ e da proporção dos gases $\left(5 \% \mathrm{~N}_{2}+95 \% \mathrm{H}_{2}, 20 \% \mathrm{~N}_{2}+80 \% \mathrm{H}_{2}, 50 \% \mathrm{~N}_{2}+50 \% \mathrm{H}_{2}\right.$ e $\left.80 \% \mathrm{~N}_{2}+20 \% \mathrm{H}_{2}\right)$ na resistência ao desgaste do aço 1020 tratado por nitretação iônica a plasma. Analisando-se a variação da temperatura, a melhor condição de resistência ao desgaste foi obtida a $450^{\circ} \mathrm{C}$. Observando-se a mudança de proporção gasosa, o melhor resultado em desgaste foi obtido para $20 \% \mathrm{~N}_{2}+80 \% \mathrm{H}_{2}$. Alterando-se os fluxos, o menor volume de desgaste foi obtido para a amostra tratada com $500 \mathrm{sccm}$. O resultado comum entre os parâmetros que proporcionaram maior resistência ao desgaste foi alcançado com a obtenção de camada composta fina e dura de nitretos na superfície tratada, devendo-se buscar esta condição para obter uma melhor resistência ao desgaste do material estudado.
\end{abstract}

Palavras-chave: Microdesgaste abrasivo, Camada composta, Fluxo gasoso.

\section{ABSTRACT}

The 1020 steel, despite presenting adequate mechanical resistance for cutting and forming aluminum alloys, it suffers wear, decreasing its efficiency in service. To avoid this, the use of thermochemical treatment could, such as ionic plasma nitriding, promote the nitrogen diffusion creating nitrides on the material surface, increasing the wear resistance, corrosion, and fatigue of the material. Then, it was studied the effect of flow $(500 \mathrm{sccm}$ e $750 \mathrm{sccm})$, temperature $\left(400,450,500,550\right.$ e $\left.600^{\circ} \mathrm{C}\right)$ and gas proportion $\left(5 \% \mathrm{~N}_{2}+95 \% \mathrm{H}_{2}\right.$, $20 \% \mathrm{~N}_{2}+80 \% \mathrm{H}_{2}, 50 \% \mathrm{~N}_{2}+50 \% \mathrm{H}_{2}$ e $80 \% \mathrm{~N}_{2}+20 \% \mathrm{H}_{2}$ ) in the wear resistance of the 1020 steel treated by plasma ion nitriding. Analyzing the temperature variation, the better wear resistance condition was obtained at $450^{\circ} \mathrm{C}$. Observing the effect of the gas proportion variation, the better wear resistance was obtained at $20 \% \mathrm{~N}_{2}+80 \% \mathrm{H}_{2}$. Altering the flow, the lower volume wear was obtained at treatment with $500 \mathrm{sccm}$. The common result among the parameters that provided the greater wear resistance was achieved by the thin and hard compound layer produced on the treated surface, and this condition should be sought to obtain a better wear resistance of the studied material.

Keywords: Microabrasive wear, Compound layer, Gas flow.

1. Faculdade de Tecnologia de Sorocaba - Sorocaba (SP), Brasil.

2. Universidade Federal de São Carlos, Campus Sorocaba, Sorocaba (SP), Brasil.

*Autor correspondente: miguelrdanelon@hotmail.com

Recebido: 14 Abr 2020 Aprovado: 22 Jun 2020 


\section{INTRODUCTION}

O aço SAE 1020 é uma liga de ferro com percentual de carbono entre 0,18 a 0,23\% p., sendo um material muito dúctil, com ótima trabalhabilidade, resistência mecânica e baixo custo ${ }^{1}$. Devido a isso, ele é utilizado para corte e conformação de alumínio. Porém, sua baixa resistência ao desgaste causa interrupções na linha de produção para reparo e manutenção dos moldes, o que diminui a eficiência do processo.

Para resolver esse problema, tratamentos de superfície podem ser realizados a fim de aumentar a dureza e a resistência ao desgaste do material, os quais podem ser realizados a plasma, que corresponde a uma tecnologia recente, eficiente e não poluente utilizada para modificação de superfície de materiais ${ }^{2-4}$.

A nitretação iônica a plasma é um tratamento termoquímico em meio de plasma em que a superfície do metal é alterada devido a difusão de nitrogênio que se combina com os elementos já presentes no substrato, formando a camada nitretada constituída por uma região conhecida como camada composta e pela zona de difusão ${ }^{5,6}$.

A camada composta é formada por nitretos que apresentam alta dureza, aumentando as propriedades mecânicas do metal como resistência ao desgaste e à fadiga, além de apresentar resistência à corrosão $0^{4,5,7}$. Quando há o bombardeamento de nitrogênio na superfície do aço, há um alto gradiente de concentração do elemento em difusão na superfície tratada, o que causa a formação dos nitretos de ferro, que se formam inicialmente pela fase rica em nitrogênio - FeN, que é instável. Esta fase então se decompõe em nitretos estáveis, em que o nitrogênio em excesso é liberado, podendo formar $\mathrm{Fe}_{2} \mathrm{~N}, \mathrm{Fe}_{3} \mathrm{~N}$ e $\mathrm{Fe}_{4} \mathrm{~N}$. As fases mais comumente encontradas nos tratamentos de nitretação são as $\mathrm{Fe}_{4} \mathrm{~N}$ e $\mathrm{Fe}_{2-3} \mathrm{~N}^{8}$.

Segundo Brunatto , o tipo de nitreto formado está relacionado à proporção de nitrogênio introduzido na atmosfera de tratamento, em que de 15 a $30 \%$ de $\mathrm{N}_{2}$ se forma preferencialmente o nitreto $\mathrm{Fe}_{4} \mathrm{~N}$ chamada de fase $\gamma^{\prime}$, que possui estrutura cristalina CFC (Cúbica de Face Centrada), a qual fornece uma menor dureza e uma maior ductilidade a camada composta. Acima de $30 \%$ de $\mathrm{N}_{2}$, pode-se dar origem à formação do nitreto $\mathrm{Fe}_{2-3} \mathrm{~N}$, denominado como fase $\varepsilon$, possuindo uma estrutura $\mathrm{HC}$ (Hexagonal Compacta), dura e frágil ${ }^{8,10}$.

Já a zona de difusão consiste em uma solução sólida intersticial e supersaturada do nitrogênio na matriz de ferro, podendo haver precipitados de nitretos em formato de "agulhas", localizando-se logo abaixo da camada composta. Esta estrutura causa uma deformação do reticulado cristalino do metal, que dificulta o movimento de discordâncias, aumentando a dureza, a resistência ao desgaste e a fadiga do material mantendo a ductilidade da camada ${ }^{2,8,11}$.

Assim, a combinação da camada formada na nitretação iônica a plasma pode aumentar a resistência ao desgaste e à corrosão do aço 1020. O objetivo deste trabalho é realizar o estudo do efeito dos parâmetros temperatura, fluxo e proporção dos gases na microestrutura, dureza e resistência ao desgaste do aço SAE 1020 nitretado a plasma. Desta forma, é possível observar se a nitretação iônica a plasma pode indicar maior eficiência deste material em serviço quando aplicado em situações de desgaste, como aqueles que acontecem nas matrizes de conformação do alumínio.

\section{MATERIAIS E MÉTODOS}

O aço SAE 1020 foi obtido laminado, com dureza média de $160 \mathrm{HV}$ e composição química apresentada na Tabela 1, determinada através do espectrômetro Ametek Spectromaxx, modelo LMF05.

Tabela 1: Composição química, \%p, do aço SAE 10201.

\begin{tabular}{|c|c|c|c|c|c|c|}
\hline Aço SAE1020 & \%C & \%Si & \%Mn & $\% \mathbf{P}$ (máx) & $\%$ (máx) \\
\hline Nominal & $0,18-0,23$ & - & $0,30-0,60$ & 0,040 & 0,050 \\
\hline Obtido & 0,188 & 0,0987 & 0,474 & 0,0643 & 0,050 \\
\hline
\end{tabular}

\section{Nitretação a plasma}

Os tratamentos de nitretação a plasma foram realizados no LabTES (Laboratório de Tecnologia e Engenharia de Superfície) localizado na Faculdade de Tecnologia de Sorocaba (FATEC-SO). O sistema de tratamento, cujo esquema representativo é apresentado na Fig. 1, é constituído por uma câmara cilíndrica em aço inox com fonte DC pulsada e uma bomba mecânica de palheta rotativa para a obtenção do vácuo. Os gases, fornecidos por cilindros individuais, são introduzidos na câmara através de fluxômetros digitais. Um medidor Pirani é utilizado para medir a pressão, e a temperatura de tratamento é determinada por um multímetro conectado a um termopar tipo K acoplado a uma amostra posicionada no eletrodo inferior (catodo ou prato de tratamento) do reator. 


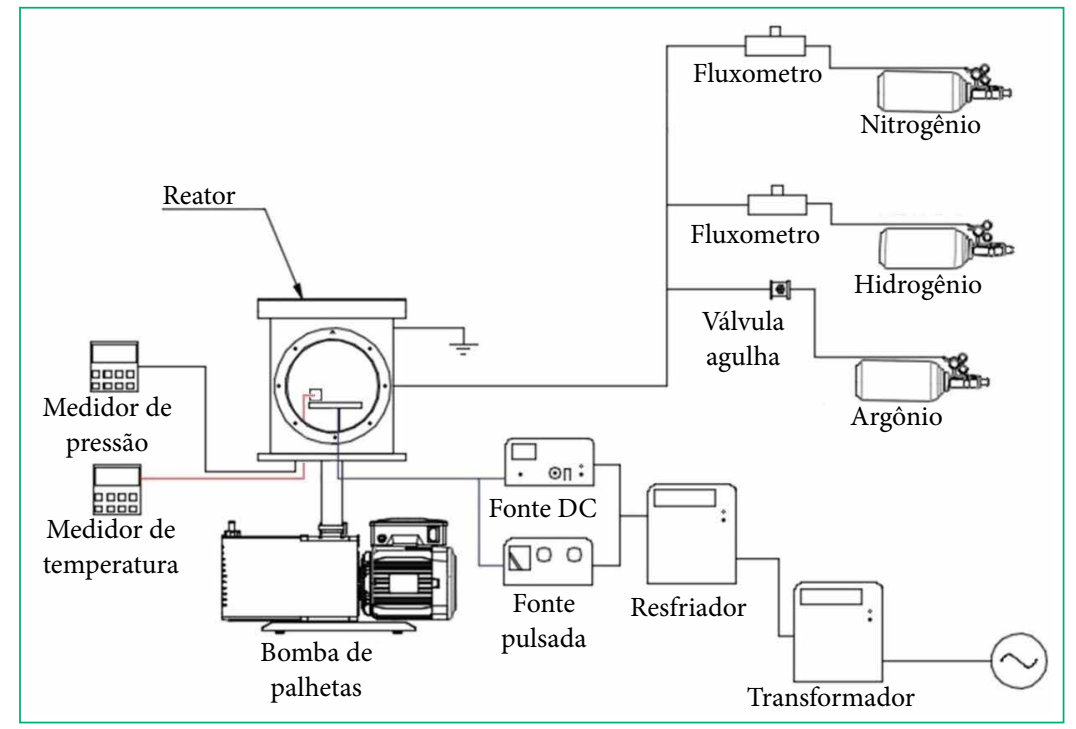

Figura 1: Sistema de tratamento a plasma.

Antes de iniciar os tratamentos, as amostras com acabamento polido foram limpas com detergente, acetona e álcool em ultrassom. Após, as amostras foram inseridas no interior do reator, posicionadas no eletrodo inferior e o sistema foi colocado em vácuo, atingindo aproximadamente $5 \times 10^{-2}$ torr. As amostras passaram pelo processo de limpeza de ablação a plasma durante $1 \mathrm{~h}$ com proporções gasosas de $80 \% \mathrm{Ar}+20 \% \mathrm{H}_{2}$, para a remoção de óxidos e impurezas na superfície das amostras ${ }^{12,13}$, atingindo a temperatura do tratamento da nitretação iônica a plasma já nesta etapa do processo. Após, os tratamentos termoquímicos de nitretação foram realizados.

Os tratamentos de nitretação iônica a plasma foram realizados variando a temperatura, a proporção e o fluxo dos gases para determinar o efeito destes parâmetros na microestrutura, na dureza e na resistência ao desgaste do material estudado. Os parâmetros utilizados no tratamento estão apresentados na Tabela 2. Deve-se salientar que, uma vez que o reator de tratamento não apresenta fonte externa de aquecimento, a temperatura é atingida a partir do ajuste da voltagem para cada condição específica, observando-se, então, uma variação da voltagem de acordo com os parâmetros de tratamento. Após os tratamentos, as amostras foram caracterizadas por metalografia, microdureza e ensaio de microdesgaste abrasivo.

Tabela 2: Parâmetros utilizados nos tratamentos de nitretação.

\begin{tabular}{|c|c|c|c|c|c|}
\hline Nomenclatura & Gases (\%) & Tempo (h) & Fluxo Total (sccm) & Tensão (V) & Temperatura $\left({ }^{\circ} \mathrm{C}\right)$ \\
\hline \multicolumn{6}{|c|}{ Tratamentos Variando a Temperatura } \\
\hline $\mathrm{NIT} 400^{\circ} \mathrm{C}$ & $80 \% \mathrm{~N}_{2}+20 \% \mathrm{H}_{2}$ & 5 & 750 & 407 & 400 \\
\hline $\mathrm{NIT} 450^{\circ} \mathrm{C}$ & $80 \% \mathrm{~N}_{2}+20 \% \mathrm{H}_{2}$ & 5 & 750 & 455 & 450 \\
\hline $\mathrm{NIT} 500^{\circ} \mathrm{C}$ & $80 \% \mathrm{~N}_{2}+20 \% \mathrm{H}_{2}$ & 5 & 750 & 523 & 500 \\
\hline $\mathrm{NIT} 550^{\circ} \mathrm{C}$ & $80 \% \mathrm{~N}_{2}+20 \% \mathrm{H}_{2}$ & 5 & 750 & 555 & 550 \\
\hline $\mathrm{NIT} 600^{\circ} \mathrm{C}$ & $80 \% \mathrm{~N}_{2}+20 \% \mathrm{H}_{2}$ & 5 & 750 & 595 & 600 \\
\hline \multicolumn{6}{|c|}{ Tratamentos Variando a Proporção dos Gases $+1400 \mathrm{sccm}$ Ar } \\
\hline NIT5N-95H & $5 \% \mathrm{~N}_{2}+95 \% \mathrm{H}_{2}$ & 5 & 500 & 291 & 500 \\
\hline NIT2ON-80H & $20 \% \mathrm{~N}_{2}+80 \% \mathrm{H}_{2}$ & 5 & 500 & 301 & 500 \\
\hline NIT5ON-50H & $50 \% \mathrm{~N}_{2}+50 \% \mathrm{H}_{2}$ & 5 & 500 & 302 & 500 \\
\hline NIT8ON-20H & $80 \% \mathrm{~N}_{2}+20 \% \mathrm{H}_{2}$ & 5 & 500 & 291 & 500 \\
\hline \multicolumn{6}{|c|}{ Tratamentos Variando o Fluxo dos Gases } \\
\hline NIT500 sccm & $80 \% \mathrm{~N}_{2}+20 \% \mathrm{H}_{2}$ & 5 & 500 & 411 & 500 \\
\hline NIT750 sccm & $80 \% \mathrm{~N}_{2}+20 \% \mathrm{H}_{2}$ & 5 & 750 & 523 & 500 \\
\hline
\end{tabular}

\section{Análise metalográfica}

A análise metalográfica das amostras com e sem tratamento foram realizadas de acordo com a norma ASTM E-395-00. Os corpos de prova foram cortados transversalmente, embutidos em baquelite de alta adesão, lixados em lixas d'água de granulometria 220, 320, 400, 600, 1200, 1500 e 2500, polidos com pasta de diamante $3 \mu \mathrm{m}$ e atacados com o reagente Nital 3\%. As análises de microestruturas foram obtidas utilizando-se um microscópio eletrônico de varredura (MEV) de bancada Hitachi modelo TM300 em modo retroespalhado. 


\section{Microdureza}

A microdureza superficial e o perfil de dureza foram realizados utilizando-se um Microdurômentro Mitutoyo Digital, com carga de 0,01kgf. Esta análise foi realizada nas amostras tratadas e no material base (MB) para comparação dos resultados.

\section{Ensaio de microdesgaste abrasivo}

O ensaio de desgaste dos materiais com e sem tratamento foram realizados em um dispositivo de microdesgaste abrasivo por esfera fixa alocado no LabTES, cujo esquema representativo é apresentado na Fig. 2. Os ensaios foram realizados sem nenhum tipo de líquido lubrificante ou abrasivo.

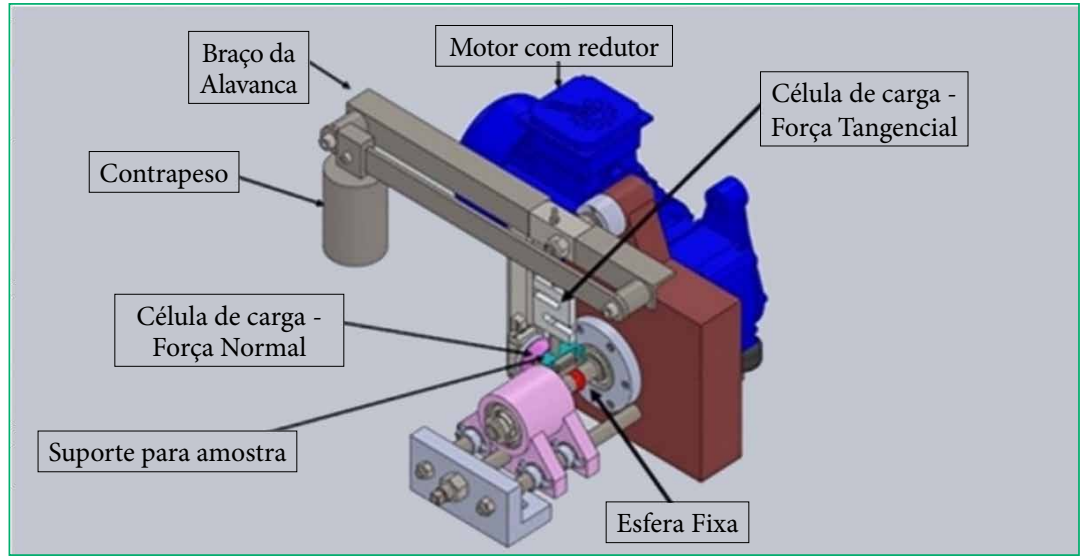

Figura 2: Microdesgaste abrasivo por esfera fixa.

Este ensaio consiste em promover o contato de uma esfera de aço em uma amostra plana com carga fixa. O resultado do contato é uma região desgastada em forma de calota esférica, possuindo relações geométricas com a esfera que a gerou. Assim, conhecendo-se o diâmetro da calota pode-se determinar a quantidade de material removido durante o ensaio.

Para uma calota de desgaste com geometria esférica produzida por uma esfera de raio "R" em uma amostra plana, foi calculado o volume (V) de desgaste para determinar a resistência ao desgaste dos materiais estudados através da equação (1), em que b corresponde ao diâmetro da calota produzida ${ }^{13}$.

Todos os ensaios foram realizados com uma carga de $8 \mathrm{~N}$, tempo de 600 s (10min) e uma frequência de rotação da esfera de $40 \mathrm{~Hz}$ ou aproximadamente 160rpm devido ao redutor do motor da máquina.

$$
V=\pi \frac{b^{4}}{64 R^{2}}\left(R-\frac{b^{2}}{8 R}\right) \approx \frac{\pi b^{4}}{64 R} \quad \text { para } \mathrm{b}<<<\mathrm{R}
$$

As medidas das calotas foram realizadas com Microscópio Óptico Leica modelo DMI8 C, localizado no Laboratório de Metalografia da FATEC-SO.

\section{RESULTADOS E DISCUSSÕES}

\section{Efeito da temperatura}

As micrografias das amostras tratadas a diferentes temperaturas podem ser observadas na Fig. 3. Em todas as amostras, observouse a formação da camada de composto de coloração clara em todas as condições de tratamento. Essa camada corresponde às ligações químicas entre o nitrogênio e o ferro, formando uma camada cerâmica de alta dureza ${ }^{8,11}$.

Logo abaixo, observou-se a formação da camada de difusão, com a presença de agulhas de nitreto na matriz metálica. Estas agulhas podem ser consideradas precipitados de nitreto que crescem a partir dos contornos de grão, por ser uma região de fácil difusão? . 


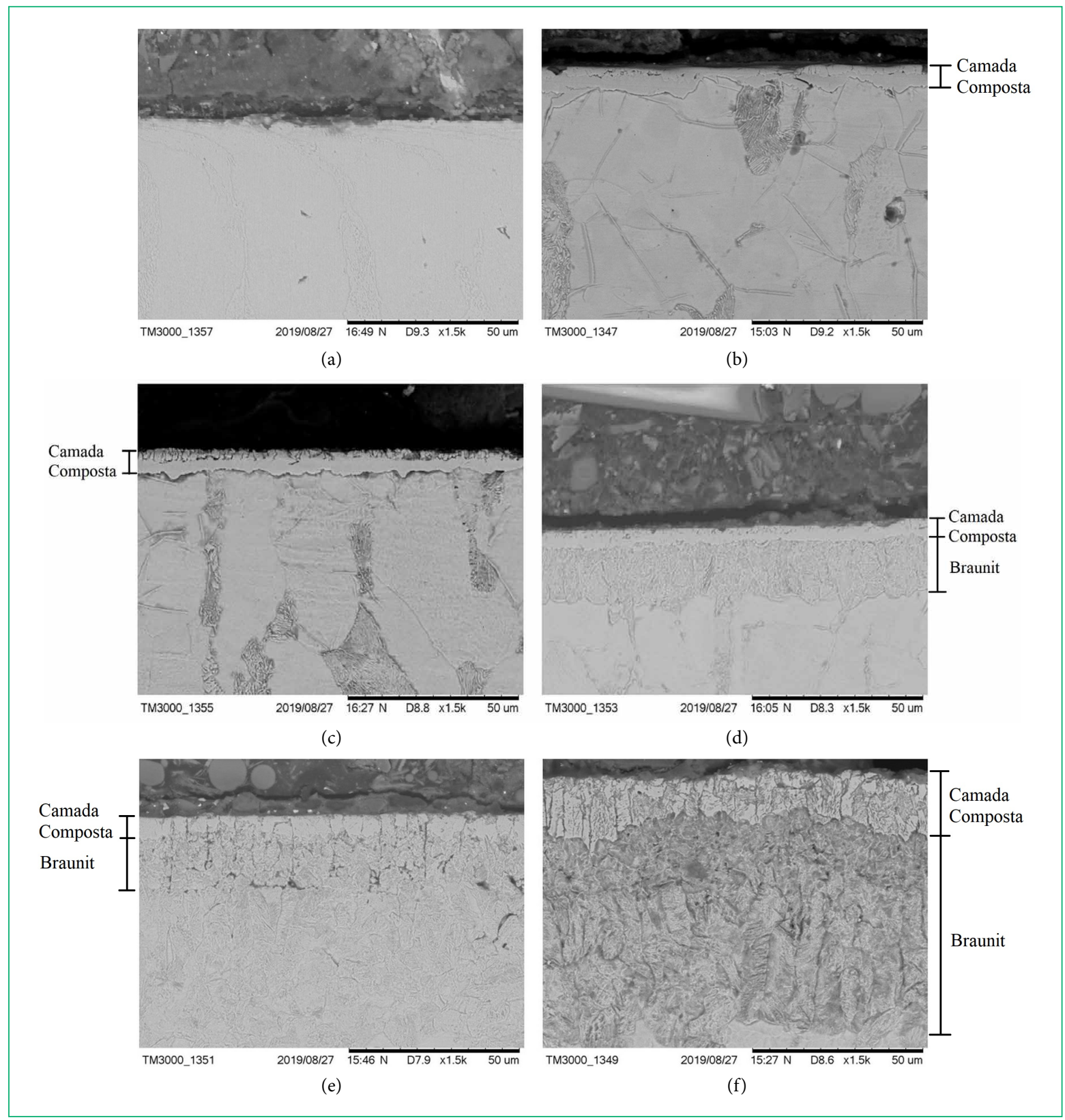

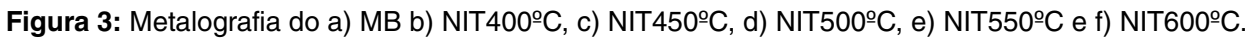

Observa-se a influência relevante da temperatura na espessura da camada formada, conforme ilustra a Fig. 4. As amostras tratadas a $400^{\circ} \mathrm{C}$ e $450^{\circ} \mathrm{C}$ apresentaram uma camada de composto de espessura menor e semelhante, comparadas às outras condições de tratamento. Porém, a amostra nitretada a $450^{\circ} \mathrm{C}$ apresentou uma camada mais uniforme, de espessura de $3,37 \mu \mathrm{m}$. Nas temperaturas acima de $500^{\circ} \mathrm{C}$ pode-se observar a formação de uma camada escura logo abaixo da camada composta que, segundo Brunatto $^{8}$, é chamada de "braunit" e é derivada da decomposição eutetóide da austenita resultante nas fases Fe - $\alpha$ e Fe4N - $\gamma$ ', durante o resfriamento da mesma após realizado o tratamento. A camada composta mais espessa foi observada para a temperatura de $600^{\circ} \mathrm{C}$, com $47,19 \mu \mathrm{m}$.

O perfil de microdureza das amostras de acordo com a temperatura de tratamento é apresentado na Fig. 5. A menor dureza obtida na camada composta foi encontrada na amostra nitretada a $400^{\circ} \mathrm{C}$, com $343 \mathrm{HV}$ e a maior na amostra nitretada a $550^{\circ} \mathrm{C}$ com $498 \mathrm{HV}$. Isto pode ser justificado pela alta concentração de nitrogênio na camada, o que fornece uma maior dureza ao material, assim como dito por Zagonel ${ }^{14}$.

A amostra nitretada a $600^{\circ} \mathrm{C}$ apresentou uma baixa dureza, próxima a amostra nitretada a $400^{\circ} \mathrm{C}$ que, segundo Fernandes ${ }^{15}$, ocorre devido à alta taxa de difusão que a temperatura proporciona, fazendo com que a quantidade de nitrogênio na camada composta seja menor e a dureza caia em relação as amostras tratadas em temperaturas menores. 


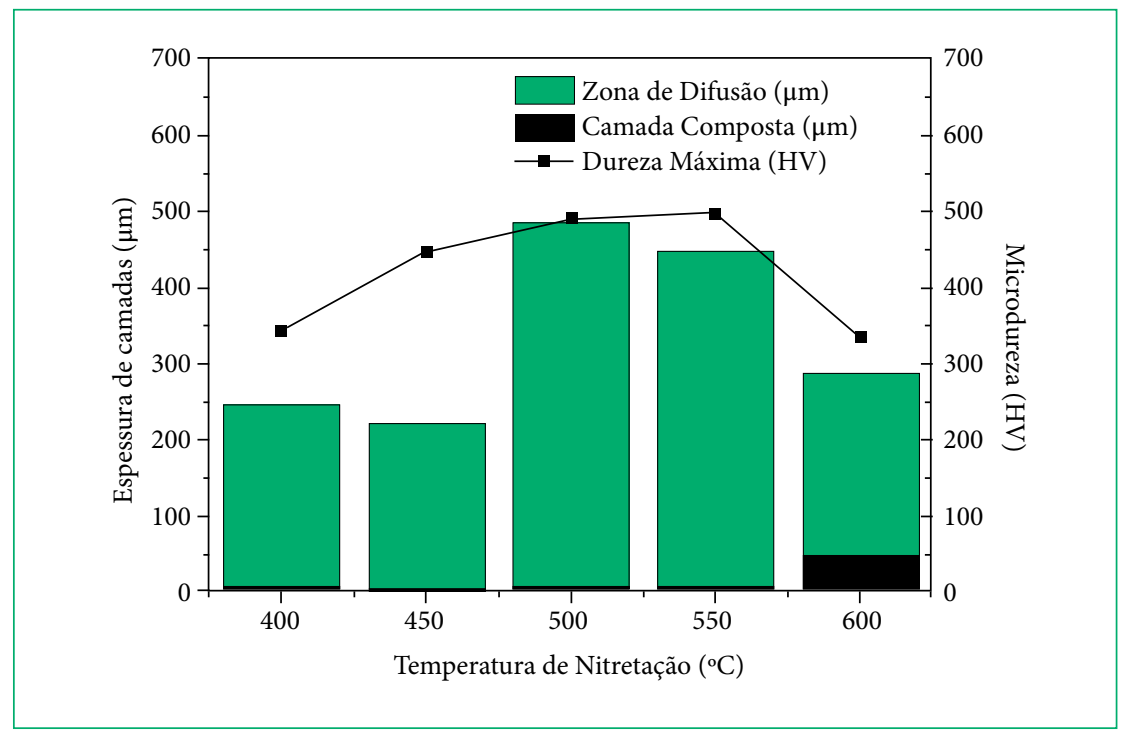

Figura 4: Espessura e dureza da camada em função da temperatura de tratamento.

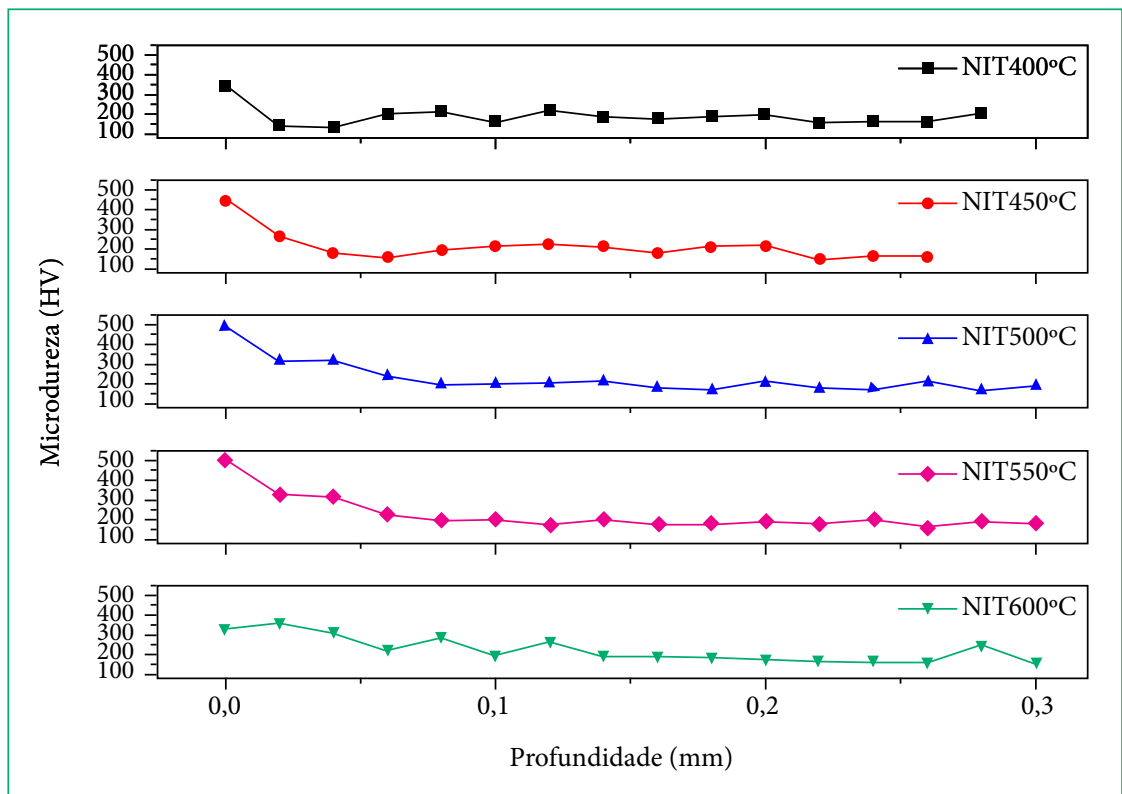

Figura 5: Perfil de microdureza para as amostras tratadas a diferentes temperaturas com $80 \% \mathrm{~N} 2-20 \% \mathrm{H} 2$ e fluxo gasoso de $750 \mathrm{sccm}$.

Os resultados de metalografia e microdureza são coerentes com o resultado obtido no ensaio de desgaste apresentado na Fig. 6 . O menor volume de desgaste foi obtido pela amostra nitretada a $450^{\circ} \mathrm{C}$, que obteve uma menor espessura de camada total (tanto de camada de difusão quanto de camada composta) e uma maior uniformidade na camada de composto, o que promove uma maior resistência ao desgaste. O resultado obtido corrobora com o observado por Pereira Neto et al. ${ }^{16}$, que analisou a resistência ao desgaste do aço Inoxidável Super duplex F53, nitretado a plasma durante $2 \mathrm{~h}$, com uma proporção gasosa de $80 \% \mathrm{~N}_{2}-20 \% \mathrm{H}_{2}$, variando a temperatura em 350 , 400 , $450,500,550$ e $570^{\circ} \mathrm{C}$. O menor volume de desgaste obtido foi na amostra nitretada a $400^{\circ} \mathrm{C}$, que apresentou uma camada de composto uniforme e de menor espessura.

Apesar da amostra nitretada a $400^{\circ} \mathrm{C}$ apresentar espessura semelhante à amostra tratada a $450^{\circ} \mathrm{C}$, esta apresentou um volume de desgaste ligeiramente superior à amostra nitretada a $450^{\circ} \mathrm{C}$, com volume de $1,71 \times 10^{-3} \mathrm{~mm}^{3}$ para a amostra NIT400 ${ }^{\circ} \mathrm{C}$ e $8,76 \times 10^{-4} \mathrm{~mm}^{3}$ na amostra $\mathrm{NIT} 450^{\circ} \mathrm{C}$ devido à uniformidade e maior dureza da camada formada na amostra NIT450 ${ }^{\circ} \mathrm{C}$. Já as camadas de composto espessas são arrancadas facilmente da superfície por serem duras e frágeis, acelerando o processo de desgaste, como foi observado para a amostra tratada a 500, 550 e $600^{\circ} \mathrm{C}^{15,17}$. Porém, o tratamento de nitretação mostrou-se eficiente no aumento da resistência ao desgaste do material, independente da temperatura, uma vez que todos os tratamentos apresentaram resistência ao desgaste superior ao material de base. 


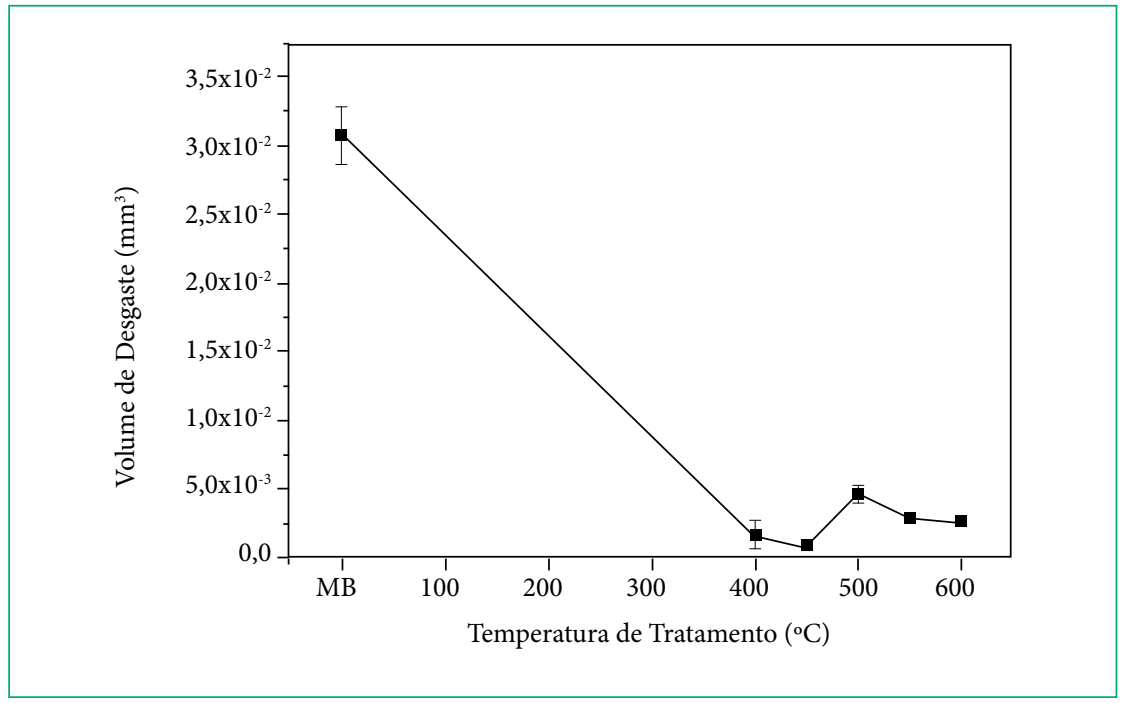

Figura 6: Volume de desgaste em função da temperatura de tratamento com $80 \% \mathrm{~N}_{2}-20 \% \mathrm{H}_{2}$ e fluxo gasoso de $750 \mathrm{sccm}$.

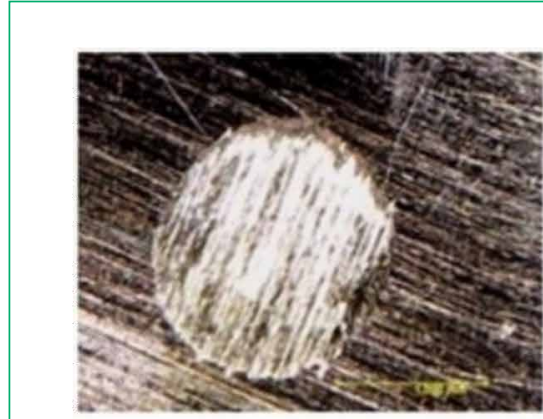

(a)

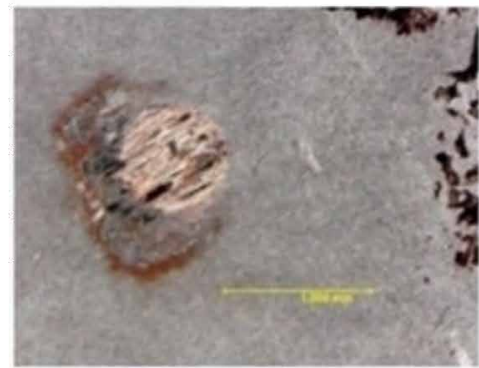

(c)

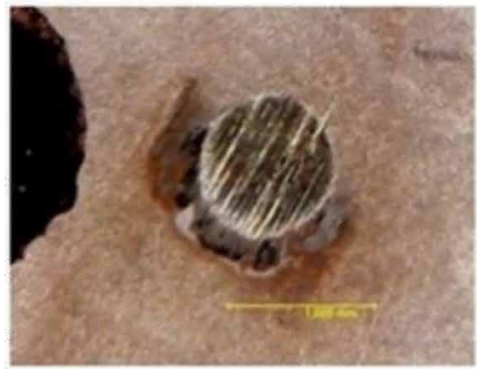

(e)

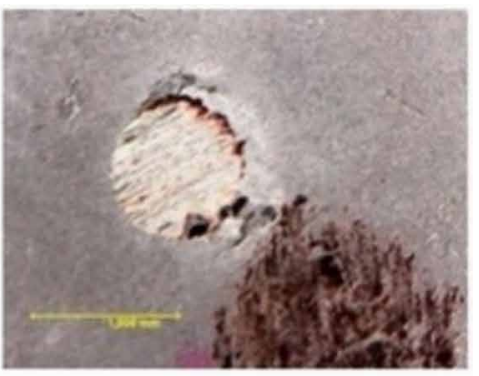

(b)

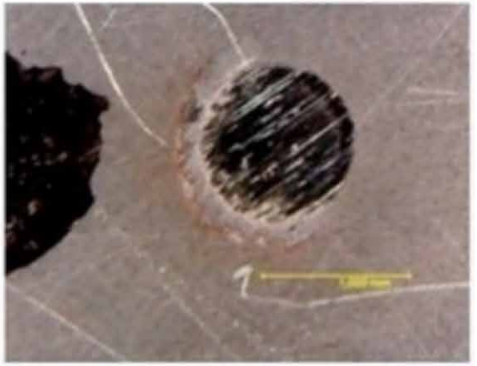

(d)

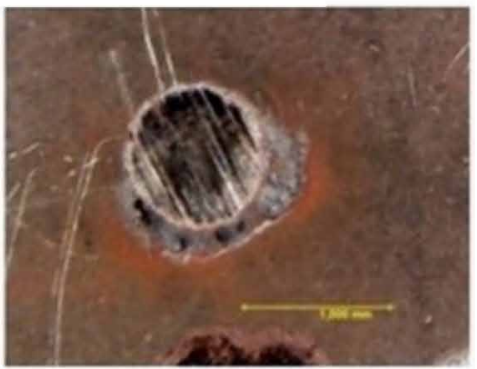

(f)

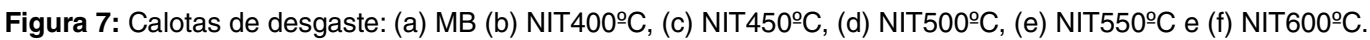

As calotas formadas no ensaio de desgaste microabrasivo por esfera fixa estão apresentadas na Fig. 7. É possível observar que, em todas as calotas, houve a formação de detritos ao redor delas. Estes detritos são resíduos das camadas compostas quando são removidas da superfície do material. A maior calota formada foi encontrada para a amostra nitretada a $500^{\circ} \mathrm{C}$, com um raio de $0,462 \mathrm{~mm}$, e a menor 
calota foi obtida para a amostra tratada a $450^{\circ} \mathrm{C}$. Fica claro, analisando as calotas, a semelhança da resistência ao desgaste das amostras tratadas entre as temperaturas de 500, 550 e $600^{\circ} \mathrm{C}$. Também foi observado a predominância do desgaste por riscamento em todos os ensaios, por ser um ensaio com alta carga e baixa quantidade de líquido abrasivo, conforme discutido nos estudos de Cozza ${ }^{18}$.

\section{Efeito da proporção gasosa}

As análises metalográficas das amostras nitretadas variando a proporção gasosa de nitrogênio e hidrogênio estão apresentadas na Fig. 8. Observa-se que a quantidade de nitrogênio presente no tratamento tem influência significativa na espessura e na existência da camada de composto.

Não foi observada a formação da camada de composto para a amostra NIT5N-95H, sendo formada apenas a zona de difusão com os nitretos precipitados em formato de agulhas. Isso ocorre devido ao baixo potencial de nitrogênio na atmosfera de tratamento, o que não é suficiente para a formação da camada de composto. Este resultado corrobora com aqueles obtidos por Brunatto ${ }^{8}$. Para a amostra NIT20N-80H, a camada composta foi a menos espessa comparada a todos os tratamentos, com espessura de 5,24 $\mu$ m. A camada de composto mais espessa foi obtida para o tratamento NIT80N-20H, com $8,17 \mu \mathrm{m}$. Segundo Basso ${ }^{11}$, com uma maior quantidade de nitrogênio na atmosfera de tratamento, maior é a difusão deste elemento para o substrato do material, e consequentemente uma camada de nitreto mais espessa é formada ${ }^{4,11}$.

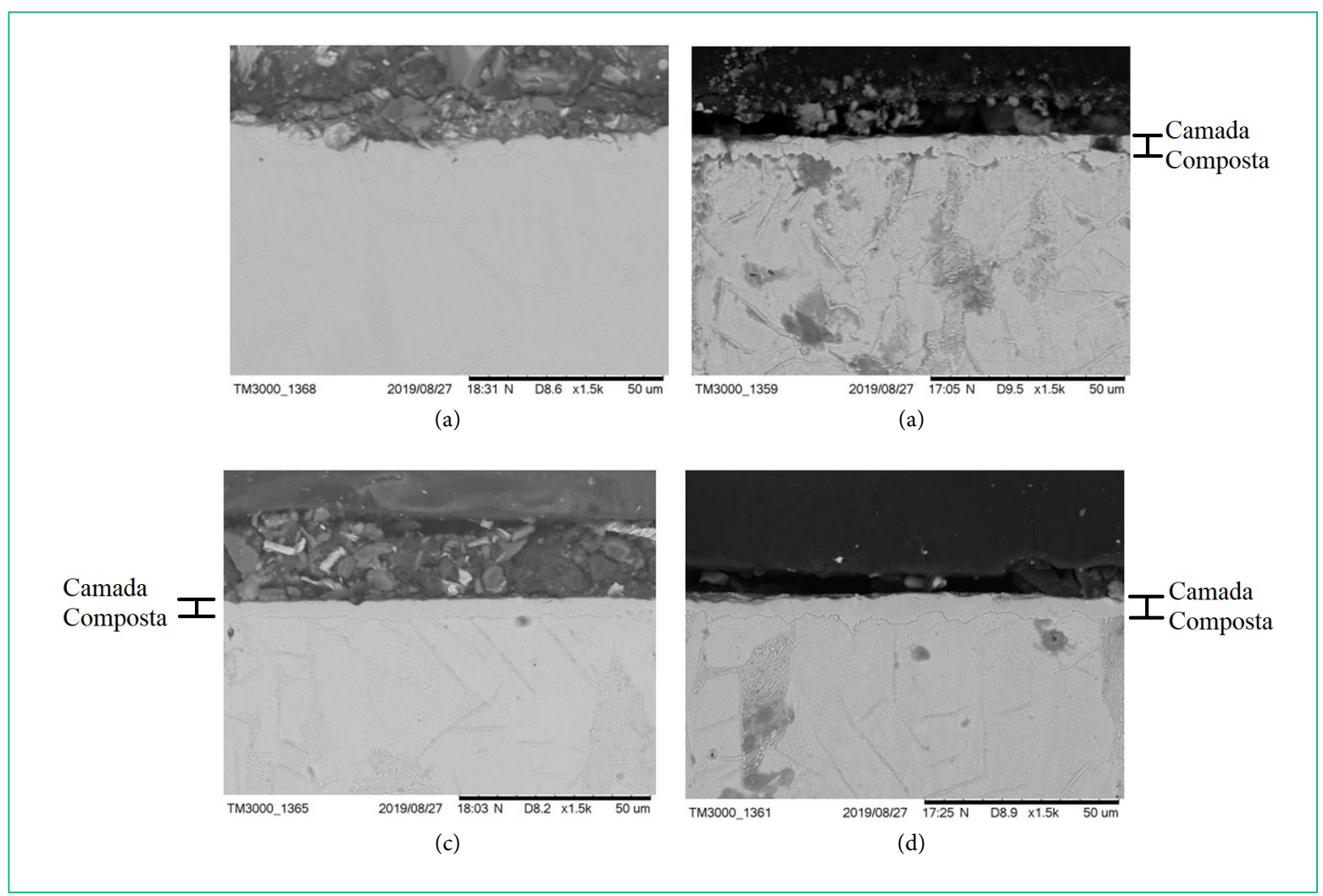

Figura 8: Metalografia das amostras a) NIT5N-95H, b) NIT20N-80H, c) NIT50N-50H e d) NIT80N-20H.

Na Fig. 9 é apresentada a relação da espessura com a dureza de cada camada obtida. Pode-se observar que a zona de difusão da amostra NIT20N-80H foi mais espessa em relação às outras amostras, mesmo tendo menor quantidade de nitrogênio na atmosfera de tratamento. Segundo Basso ${ }^{11}$, uma maior quantidade de $\mathrm{H}_{2}$ na mistura gasosa de tratamento aumenta a espessura da zona de difusão formada no material, em uma mistura que possua quantidade de nitrogênio suficiente para haver difusão deste elemento na matriz metálica. A amostra em questão também apresentou uma maior dureza em relação às outras amostras, o que Karakan ${ }^{19}$ justifica com a presença de $\mathrm{H}_{2}$, dizendo que em uma mistura gasosa com maior proporção de hidrogênio e que há formação de camada composta, a espessura da camada composta é reduzida e assim a dureza é aumentada. Esta discussão corrobora com o resultado encontrado neste trabalho, uma vez que se observou a diminuição da dureza da camada de acordo com o aumento de nitrogênio na proporção gasosa. 
Já para a amostra NIT5N-95H, não se observou a formação de camada composta e obteve-se uma menor zona de difusão comparada às outras amostras. Isto pode ser justificado pela quantidade de nitrogênio que não é alta o suficiente para que haja difusão deste elemento no material, limitando a espessura da camada formada.

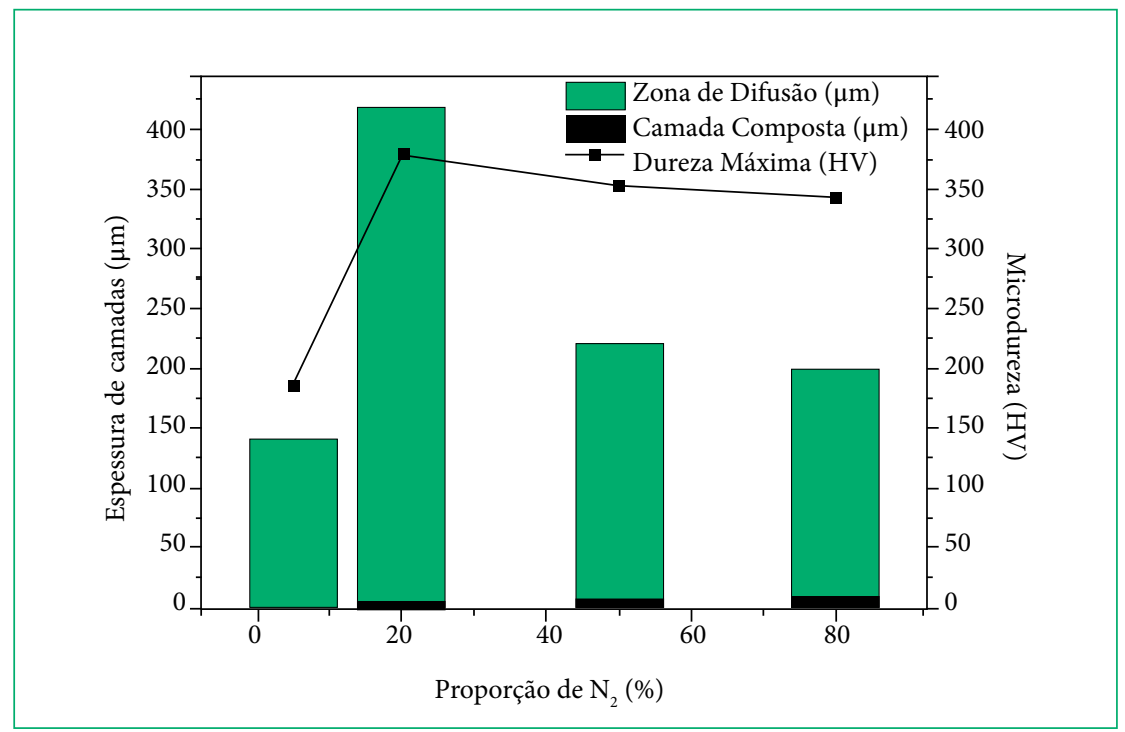

Figura 9: Espessura e dureza superficial das amostras tratadas em função da proporção de nitrogênio.

De acordo com o perfil de dureza apresentado na Fig. 10, a amostra NIT20N-80H obteve a maior dureza superficial, a qual se manteve em maior profundidade, evidenciando a formação de uma maior zona de difusão. Como já dito anteriormente, isto está relacionado à presença de $\mathrm{H}_{2}$ na mistura gasosa, o qual proporciona uma maior zona de difusão e maior dureza devido a redução na espessura da camada composta. A menor dureza superficial foi encontrada na amostra NIT5N-95H, uma vez que nesta condição não se formou a camada de composto.

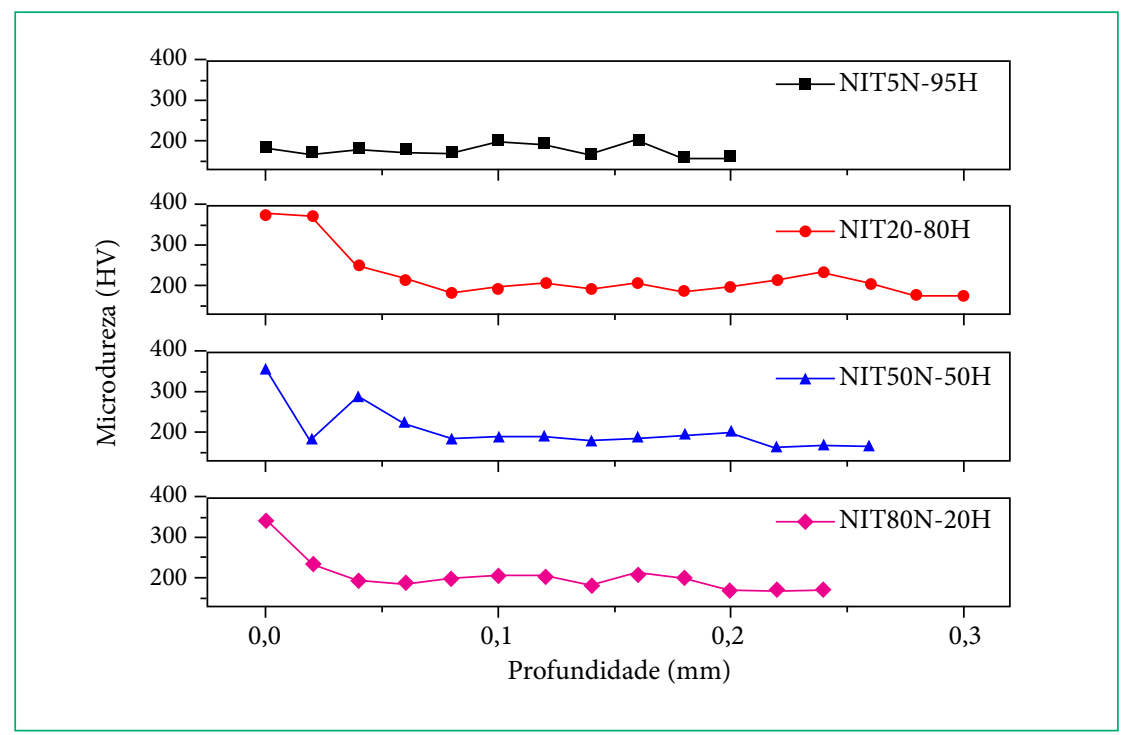

Figura 10: Perfil de dureza das amostras tratadas em função da proporção de nitrogênio a $500^{\circ} \mathrm{C}$ e fluxo gasoso de $500 \mathrm{sccm}+1400 \mathrm{sccm}$ de Ar.

Analisando os volumes de desgaste, apresentados na Fig. 11, pode-se observar que o menor volume de desgaste foi encontrado para a amostra NIT20H-80H, cujo resultado foi muito semelhante a amostra NIT50N-50H apresentando $1,89 \times 10^{-3} \mathrm{~mm}^{3}$ e $2,25 \times 10^{-3} \mathrm{~mm}^{3}$, respectivamente. Este resultado é explicado pela dureza, espessura e uniformidade da camada formada ${ }^{15}$. 
Os maiores volumes de desgaste dos corpos de prova nitretados foram encontrados nas amostras NIT5-95H e NIT80N-20H, com $6,09 \times 10^{-3} \mathrm{~mm}^{3}$ e $5,39 \times 10^{-3} \mathrm{~mm}^{3}$, respectivamente. Isto é justificado na amostra NIT5N-95H pela ausência de camada composta, a qual possui uma baixa dureza, o que acelera o processo de desgaste por não haver a camada cerâmica de proteção superficial. A amostra NIT80N-20H apresentou uma baixa resistência ao desgaste devido a espessura da camada ser maior, o que proporciona uma camada frágil e quebradiça, colaborando para o desgaste do material ${ }^{15,18}$.

Independente da mistura gasosa utilizada, todas as condições de tratamento apresentaram uma melhoria na resistência ao desgaste em relação ao material base.

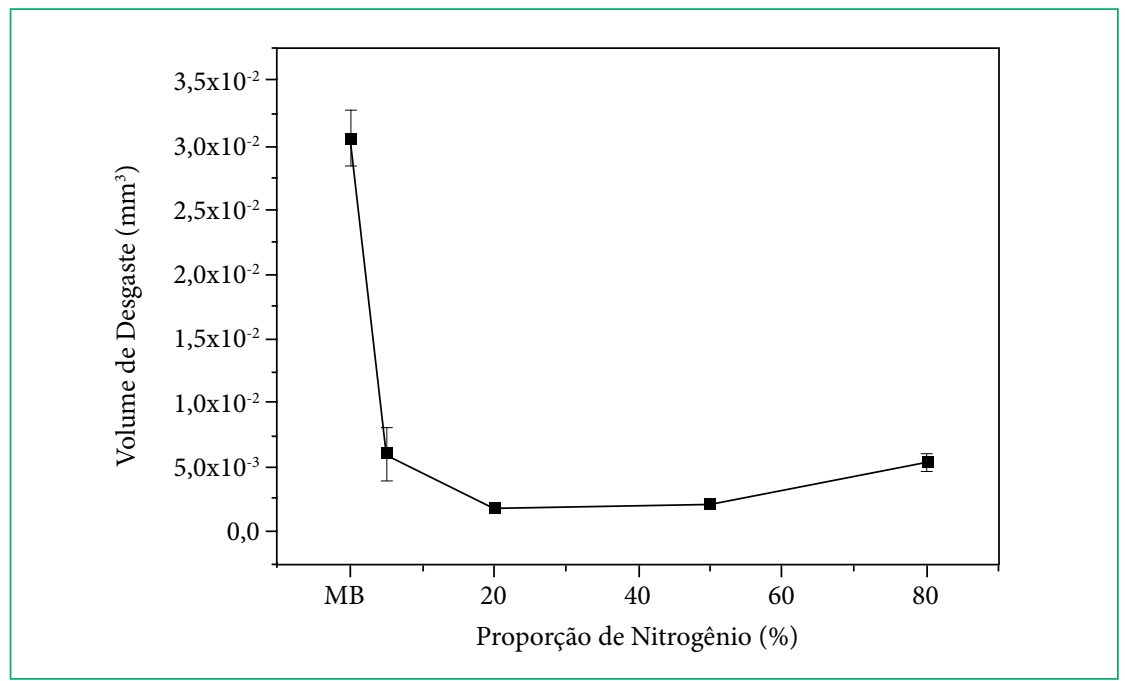

Figura 11: Volume de desgaste em função da proporção de nitrogênio a $500^{\circ} \mathrm{C}$ com fluxo gasoso de $500 \mathrm{sccm}$.

As calotas formadas no ensaio de microdesgaste abrasivo por esfera fixa estão apresentadas na Fig. 12. Da mesma forma que as amostras tratadas variando a temperatura, as calotas obtidas nos tratamentos variando a proporção dos gases também apresentaram detritos ao redor da calota, formados devido ao arranchamento de material das amostras estudadas. A menor calota formada foi para a amostra NIT20N$80 \mathrm{H}$, com raio de $0,436 \mathrm{~mm}$. Já a maior calota, dentre as tratadas, foi observada para a amostra NIT5N-95H, com raio de 0,523 mm.

É possível observar as semelhanças entre as dimensões das calotas das amostras NIT20N-80H e NIT50N-50H. A predominância do desgaste por riscamento fica evidente, característica comum em amostras em que o ensaio foi realizado com uma alta carga e baixa presença de líquido abrasivo segundo Cozza ${ }^{18}$.

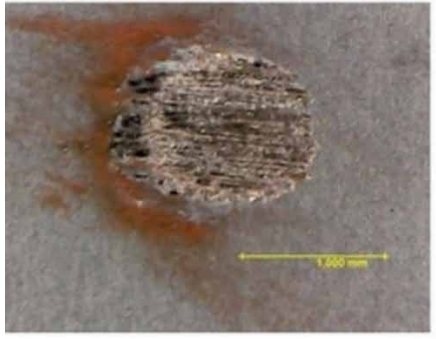

(a)

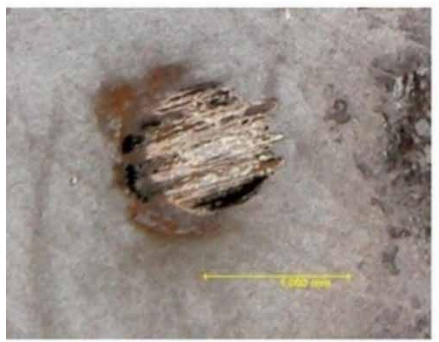

(c)

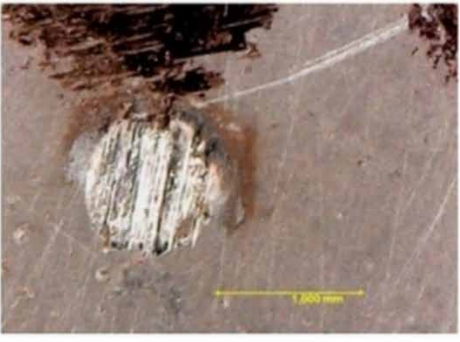

(b)

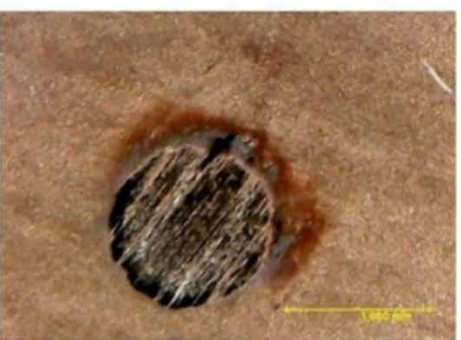

(d)

Figura 12: Calotas de desgaste dos materiais tratados: a) NIT5N-95H, b) NIT20N-80H, c) NIT50N-50H e d) NIT80N-20H. 


\section{Efeito do fluxo}

A metalografia das amostras tratadas com os fluxos gasosos de 500 e $750 \mathrm{sccm}$ estão apresentadas na Fig. 13. A camada de menor espessura foi obtida para a amostra NIT500 sccm, com espessura de 4,08 $\mu \mathrm{m}$, apresentando camada composta homogênea e as agulhas na zona de difusão. Já na amostra NIT750 sccm, com maior espessura de camada, de 5,12 $\mu \mathrm{m}$, apresentou a camada de composto, a camada "braunit"s e a zona de difusão com os nitretos precipitados.

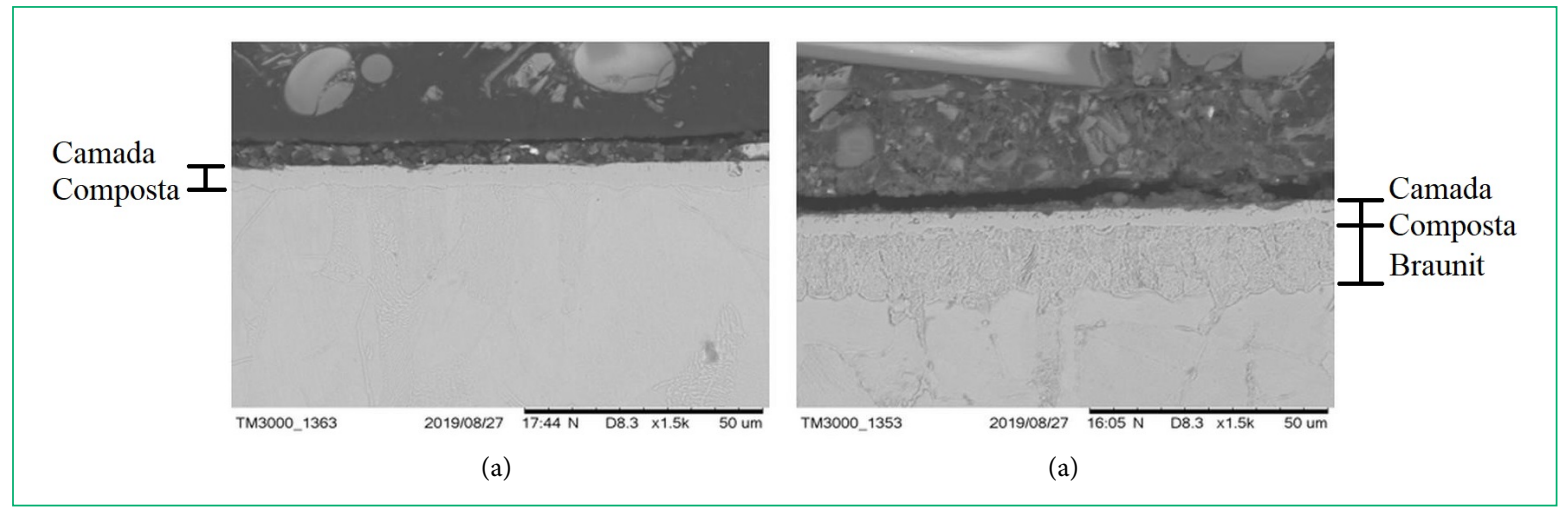

Figura 13: a) NIT500 sccm, b) NIT750 sccm.

A Fig. 14 apresenta a relação entre a espessura e a dureza superficial em função do fluxo gasoso estudado. As espessuras da zona de difusão e da camada composta da amostra tratada com $750 \mathrm{sccm}$ foram superiores em relação a amostra NIT500 sccm. Isto ocorre devido a quantidade de nitrogênio na atmosfera de tratamento, o que promove uma maior difusão do elemento na matriz metálica ${ }^{4,11}$.

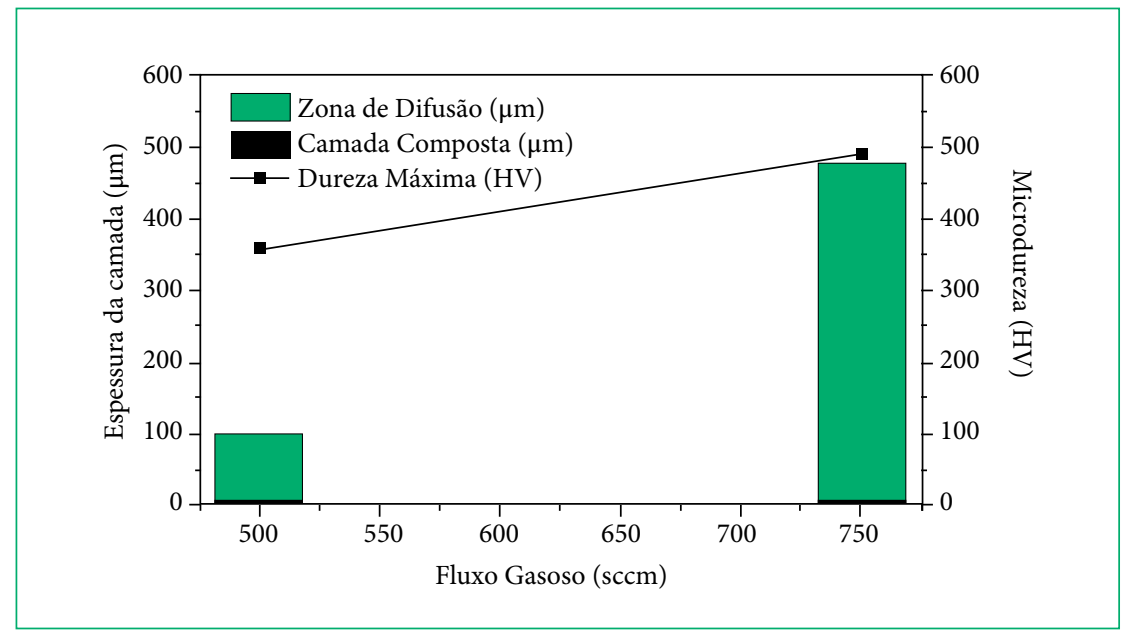

Figura 14: Espessura das camadas e dureza superficial em função do fluxo gasoso.

A Fig. 15 apresenta os perfis de dureza das amostras nitretadas com variação do fluxo gasoso. A amostra NIT750 sccm apresentou uma maior dureza em relação a amostra nitretada NIT500 sccm. Outra observação a ser feita é que a dureza em profundidade foi maior na amostra NIT750 sccm comparada a amostra NIT500 sccm. Isto ocorre justamente devido ao maior fluxo gasoso, proporcionando maior difusão do nitrogênio na matriz metálica.

Os volumes de desgaste das amostras estão apresentados na Fig. 16. A amostra NIT500sccm apresentou maior resistência ao desgaste comparada a amostra NIT750 sccm, com volumes de desgaste de $8,05 \times 10^{-4} \mathrm{~mm}^{3}$ e $4,63 \times 10^{-3} \mathrm{~mm}^{3}$, respectivamente. A espessura da camada se mostrou um fator mais relevante do que a dureza na resistência ao desgaste, em que o material que obteve uma camada composta de menor espessura (NIT500 sccm) apresentou uma maior resistência ao desgaste do que a amostra com camada de maior dureza (NIT750 sccm). Isto indica que uma camada de composto mais espessa é mais quebradiça, soltando-se com maior facilidade do substrato, prejudicando o desempenho no ensaio de desgaste ${ }^{15}$. Porém, independente da condição realizada, todos os tratamentos apresentaram melhora significante na resistência ao desgaste em relação ao material base. 


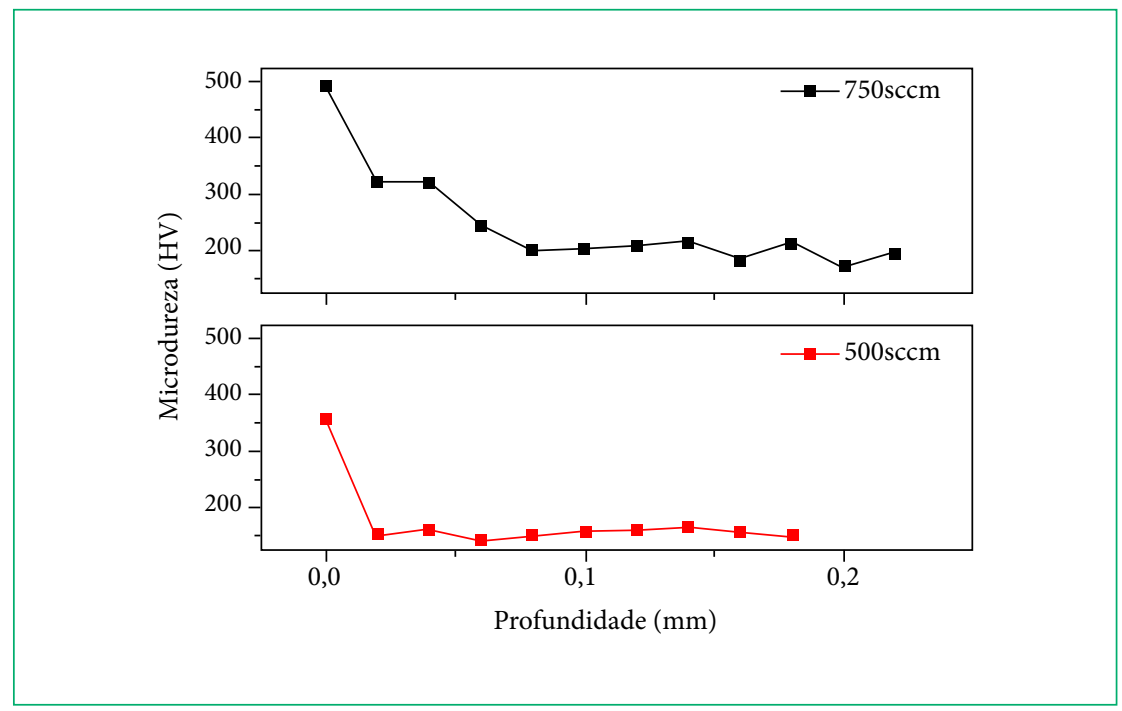

Figura 15: Perfil de dureza das amostras tratadas com fluxo gasoso de $500 \mathrm{sccm}$ e $750 \mathrm{sccm}$ a $500^{\circ} \mathrm{C}$ e $80 \% \mathrm{~N}_{2}-20 \% \mathrm{H}_{2}$.

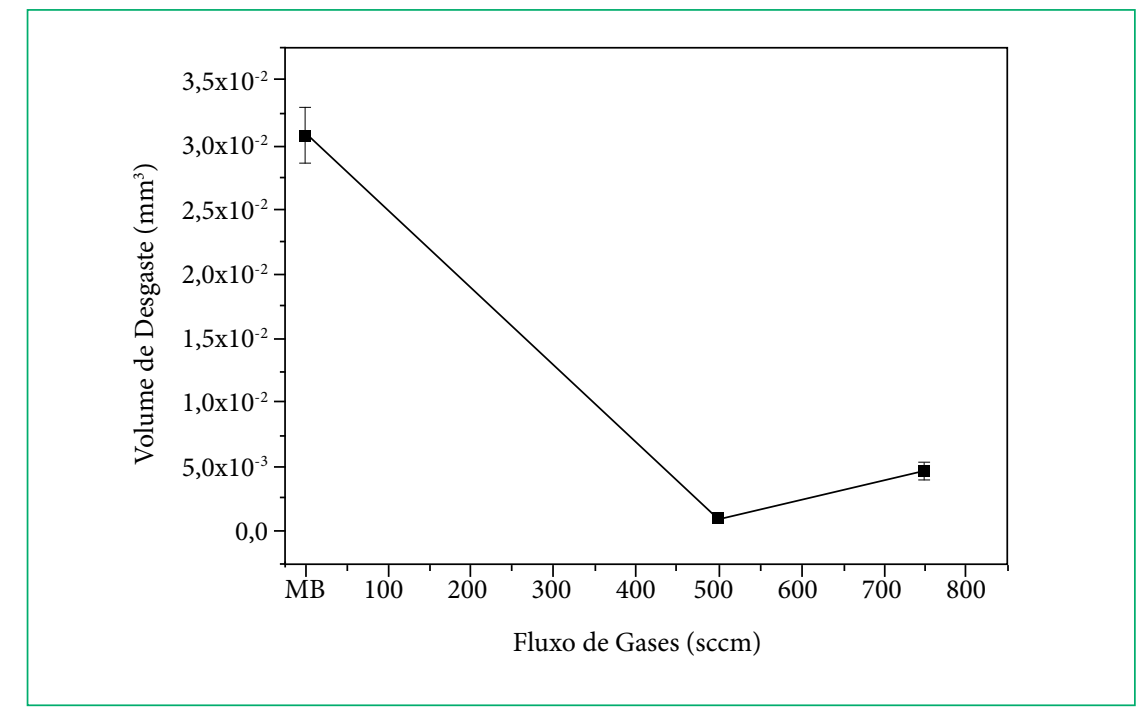

Figura 16: Volume de desgaste em função do fluxo dos gases utilizado $80 \% \mathrm{~N}_{2}-20 \% \mathrm{H}_{2}$ a $500^{\circ} \mathrm{C}$.

As calotas obtidas pelos ensaios de microdesgaste abrasivo estão apresentadas na Fig. 17, em que a amostra com menor calota foi a tratada com $500 \mathrm{sccm}$, com um raio de $0,360 \mathrm{~mm}$, enquanto que a amostra tratada a $750 \mathrm{sccm}$ apresentou uma calota com raio de $0,535 \mathrm{~mm}$. Observa-se detritos ao redor das calotas, com característica de desgaste por riscamento ${ }^{17}$.

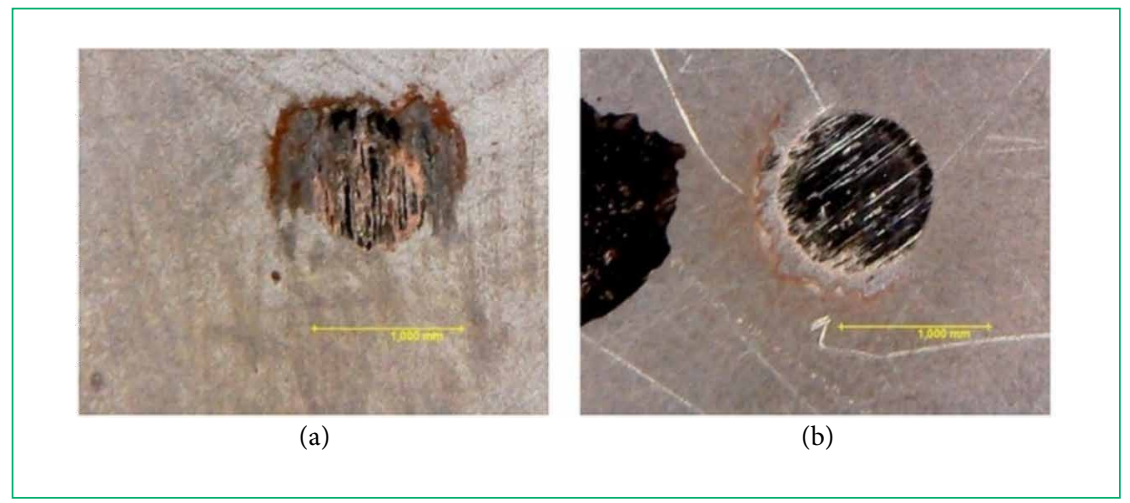

Figura 17: Calotas dos materiais tratados com fluxos gasosos: a) $500 \mathrm{sccm}$ e b) $750 \mathrm{sccm}$. 


\section{CONCLUSÃO}

De acordo com as análises realizadas e o material estudado, pode-se dizer que a nitretação iônica a plasma se mostrou uma ótima técnica para a melhoria da propriedade de resistência ao desgaste no aço SAE 1020, sendo apto a ser utilizado para aumentar o desempenho de ferramentas para ser empregado na função de corte e conformação do alumínio.

Independentemente da condição de tratamento, a nitretação iônica a plasma aumentou consideravelmente a resistência ao desgaste do material estudado. Este comportamento foi observado mesmo para a condição de tratamento NIT5N-95H, onde não houve a formação da camada composta na superfície tratada.

Ainda que a resistência ao desgaste foi melhorada independente da condição de tratamento realizada, a temperatura de $450^{\circ} \mathrm{C}$, a proporção gasosa de $20 \% \mathrm{~N}_{2}-80 \% \mathrm{H}_{2}$ e o fluxo gasoso de $500 \mathrm{sccm}$ foram os parâmetros que proporcionaram a maior resistência ao desgaste para o material estudado. Este resultado é influenciado pela homogeneidade, dureza e espessura da camada formada.

A presença da camada de composto, uniforme e de pequena espessura, é essencial, e se mostra o principal parâmetro, para se obter a melhor eficácia em desgaste do material, como observado nas amostras NIT450 ${ }^{\circ} \mathrm{C}$, NIT20N-80H e NIT500sccm que obtiveram volume de desgaste de $8,75 \times 10^{-4} \mathrm{~mm}^{3}, 1,89 \times 10^{-3} \mathrm{~mm}^{3}$ e $8,05 \times 10^{-4} \mathrm{~mm}^{3}$, respectivamente. Comparando estas três condições de tratamento, a amostra NIT20N-80H apresentou menor resistência ao desgaste pois sua camada foi a mais espessa dentre estas amostras, com $5,24 \mu \mathrm{m}$ enquanto as amostras NIT $450^{\circ} \mathrm{C}$ e NIT500 sccm obtiveram espessura de $3,37 \mu \mathrm{m}$ e $4,08 \mu \mathrm{m}$, respectivamente. Uma camada de composto mais espessa proporciona uma maior fragilidade à camada, que facilita o seu desprendimento da superfície, acelerando o processo de desgaste.

Assim, deve-se determinar os parâmetros de tratamento de forma adequada para que se alcance o melhor resultado em desgaste para o material a ser aplicado em serviço.

\section{AGRADECIMENTOS}

Os autores agradecem ao CNPq (167181/2018-1) pelo auxílio financeiro.

\section{REFERENCES}

1. GGD Metals. Catálogo técnico aços e metais; 2015. Disponível em: https://ggdmetals.com.br/wp-content/uploads/2019/04/GuiaGGDMetalsConstrução-Mecânica.pdf

2. Alves Junior C, Rodrigues JA, Martinelli AE. The effect of pulse width on the microstructure of d.c.-plasma-nitrided layers. Surface \& Coatings Technology 1999;122(2-3):112-17. https://doi.org/10.1016/S0257-8972(99)00326-6

3. Grün R, Günther H-J. Plasma nitriding in industry_-problems, new solutions and limits. Materials Science and Engineering: A 1991;140:43541. https://doi.org/10.1016/0921-5093(91)90459-Z

4. Holm T, Sproge L. Furnace atmospheres 3: nitriding and nitrocarburizing. Report GIM 89267, AGA, Lidingö.1989.

5. Alves Junior C. Nitretação a plasma: fundamentos e aplicações. Natal: EDUFRN, 2001. Disponível em: https://repositorio.ufrn.br/jspui/ handle/1/11807

6. Sousa RRM de, Moura YJL, Sousa PAO de, Medeiros Neto JQ, Costa THC, Alves Junior C. Nitriding of AISI 1020 steel: comparison between conventional nitriding and nitriding with cathodic cage. Materials Research 2014;17(3): 708-13. https://doi.org/10.1590/S151614392014005000027

7. Fontana LC et al. Nitretação a plasma como meio alternativo ou complementar à oxidação negra na proteção à corrosão do aço de baixo teor de carbono. Matéria 2004;9(4):360-69.

8. Spalvins T. Plasma assisted surface coating/modification processes: an emerging technology. In: First International lon Nitriding Conference consponsored by the American Society of Metals and NASA Lewis Research Center; 1986 Sept 15-17: Cleveland, Ohio. Disponível em: https://ntrs.nasa.gov/archive/nasa/casi.ntrs.nasa.gov/19870003275.pdf

9. Brunatto SF, Muzart JLR, Klein AN. Nitretação por plasma de ferro sinterizado. In: 10 CBECIMAT; 1992; Águas de Lindóia, SP. Anais do 10 CBECIMAT, 1992. v. 1. p.847-850

10. Basso RLO, Figueroa CA, Zagonel LF, Pastore HO, Alvarez DWF. Effect of carbon on the compound layer properties of AISI $\mathrm{H} 13$ tool steel in pulsed plasma nitrocarburizing. Plasma Processes and Polymers 2007;4(S1):S728-S731. https://doi.org/10.1002/ppap.200731806

11. Fanchin F, Rodrigues JA, Casteletti LC. Nitretação por plasma pulsado de aço do tipo SAE 1011: caracterização da camada nitretada. Revista Brasileira de Aplicações de Vácuo 2000;19(2):16-23. http://doi.org/10.17563/rbav.v19i2.200

12. Silva MAM, Guerra Neto CLB, Coutinho KD, Wanderley CDV Guerra PVA. Limpeza a plasma para melhorar a adesão superficial de filmes de oxido de titânio. Revista Brasileira de Inovação Tecnológica em Saúde. 2012;2(4):8-46. https://doi.org/10.18816/r-bits.v2i4.3392 
13. Petasch W, Kegel B, Schmid H, Lendenmann K, Keller HU. Low-pressure plasma cleaning: a process for precision cleaning applications. Surface and Coatings Technology. 1997;97:176-81. https://doi.org/10.1016/S0257-8972(97)00143-6

14. Rutherford KL, Hutchings IM. A micro-abrasive wear test with particular application to coated systems. Surface and Coatings Technology. 1996;79:231-39. https://doi.org/10.1016/0257-8972(95)02461-1

15. Zagonela LF, Figueroa CA, Droppa Jr. R, Alvareza F. Influence of the process temperature on the steel microstructure and hardening in pulsed plasma nitriding. Surface and Coatings Technology. 2006;201(1-2):452-57. https://doi.org/10.1016/j.surfcoat.2005.11.137

16. Fernandes FAP, Heck SC, Picone CA, Casteletti LC. On the wear and corrosion of plasma nitrided AISI H13. Surface and Coatings Technology. 2020;381:125216. https://doi.org/10.1016/j.surfcoat.2019.125216

17. Pereira Neto JO, Silva RO, Silva EH, Moreto JA, Bandeira RM, Manfrinato MD, Rossino LS. Wear and Corrosion Study of Plasma Nitriding F53 Super duplex Stainless Steel." Materials Research. 2016 Dec;19(6): 1241-52. https://doi.org/10.1590/1980-5373-mr-2015-0656

18. Cozza RC. Study of the steady state of wear in micro-abrasive wear tests by rotative ball conducted on specimen of WC-Co P20 and M2 tool-steel. Matéria. 2018;23(1):1-13. https://doi.org/10.1590/s1517-707620170001.0322

19. Karakan M, Alsaran A, Çelik A. Effects of various gas mixtures on plasma nitriding behavior of AISI 5140 steel. Materials Characterization 2002;49(3):241-46. https://doi.org/10.1016/S1044-5803(03)00010-X 